\title{
Are the clinical benefits of oral prenalterol in ischaemic heart failure due to beta blockade? \\ A six month randomised double blind comparison with placebo
}

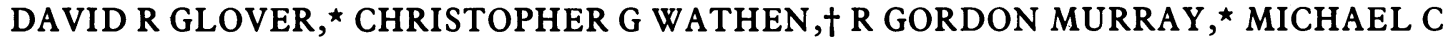 \\ PETCH, $\ddagger$ ALEXANDER L MUIR, $†$ WILLIAM A LITTLER*
}

From the Departments of Cardiovascular Medicine, ${ }^{\star}$ East Birmingham Hospital, Birmingham, $†$ Royal Infirmary, Edinburgh; and $\ddagger$ Papworth Hospital, Cambridge.

SUMMARY The clinical effects of the oral beta ${ }_{1}$ partial agonist, prenalterol, were investigated in 37 patients (29 male, eight female; mean age 57 years) with chronic ischaemic left ventricular failure using a placebo controlled randomised double blind protocol over six months. All patients were limited by dyspnoea (New York Heart Association class III) despite treatment with digoxin and diuretics. Twenty eight patients completed the protocol. Moderate clinical improvement was seen in the prenalterol group, whereas there was little change in the placebo group. Bicycle exercise capacity increased over six months in the prenalterol and placebo groups but only achieved statistical significance for prenalterol when compared with baseline values. Maximum exercise heart rate was significantly reduced in the prenalterol group compared with placebo. Radionuclide left ventricular ejection fraction at rest and during exercise and cardiothoracic ratio showed no significant improvement in either group over six months. Prenalterol was well tolerated and produced no increase in frequency of angina or ventricular arrhythmias.

Prenalterol produced clinical benefits and improved exercise tolerance while reducing exercise heart rate. A moderate placebo response was noted. The apparent beta blocking effect of prenalterol may be as important as the beta ${ }_{1}$ agonist effect in producing these benefits. Prenalterol has, however, been withdrawn because of side effects in animals.

The management of patients with chronic ischaemic left ventricular failure is often difficult and unsatisfactory and usually requires multiple drug treatment. ${ }^{1}$ The prognosis is poor despite treatment. ${ }^{2}$ The conventional management is with diuretics and cardiac glycosides, ${ }^{1}$ and, although the role of cardiac glycosides remains controversial, ${ }^{34}$ recent studies have confirmed that some inotropic support is maintained in patients in sinus rhythm, ${ }^{5-7}$ especially those with an audible third heart sound. ${ }^{8}$ In the past decade there has been increasing interest in both vasodilator

Requests for reprints to Dr D R Glover, Department of Cardiovascular Medicine, East Birmingham Hospital, Bordesley Green East, Birmingham B9 5ST.

Accepted for publication 25 September 1984 treatment ${ }^{910}$ and inotropic drugs, particularly amrinone ${ }^{11}$ and beta agonists.

The role of beta agonists in the management of heart failure has recently been reviewed.1213 The beta $_{2}$ agonists salbutamol and pirbuterol produce beneficial effects mainly by vasodilatation. ${ }^{14}$ At present, there are apparently only two orally active selective beta ${ }_{1}$ partial agonists: prenalterol and xamoterol [Corwin] (maximum agonist activity is $80 \%{ }^{15}$ and $43 \%^{16}$ of that of isoprenaline respectively). Both drugs exert a positive inotropic effect acutely 1617 and during short term maintenance treatment. ${ }^{18} 19$ There is, however, a need for long term placebo controlled studies of these drugs in the management of left ventricular failure. ${ }^{13}$ The occurrence of side effect in animals has led to the withdrawal of prenalterol, but our studies may be of more general interest. 
Table 1 Patient characteristics. Figures are numbers of patients unless stated otherwise

\begin{tabular}{lll}
\hline & Prenalterol & Placebo \\
\hline No of patients & 19 & 18 \\
Male/female & $13 / 6$ & $16 / 2$ \\
Mean (SD) (yr) & $57(6 \cdot 8)$ & $57(7 \cdot 3)$ \\
Mean (SD) weight (kg) & $66(10 \cdot 0)$ & $71(11 \cdot 5)$ \\
Mean (SD) ejection fraction & $0 \cdot 27(0 \cdot 119)$ & $0 \cdot 26(0.076)$ \\
Mean (SD) duration of left & $2(2 \cdot 2)$ & $2(1 \cdot 3)$ \\
$\quad$ ventricular failure (yr) & 18 & 14 \\
Previous myocardial infarction & 19 & 18 \\
NYHA class III & 7 & 7 \\
Angina present & 4 & 3 \\
Atrial fibrillation & & $0.23(0.050)$ \\
Mean (SD) dose (mg): & $0.25(0.079)$ & $120(54 \cdot 8)$ \\
$\quad$ Digoxin & $107(65 \cdot 9)$ & 7 \\
$\quad$ Frusemide & 7 & \\
Antianginal treatment & & \\
\hline
\end{tabular}

No statistically significant differences prenalterol vs placebo.

In this study the clinical effects of the beta ${ }_{1}$ partial agonist prenalterol were assessed using a placebo controlled double blind protocol of six months' duration in patients with stable chronic ischaemic left ventricular failure.
Patients and methods

\section{STUDY POPULATION}

Patients were recruited during routine outpatient practice at three centres (Birmingham, Edinburgh, and Cambridge). A total of 37 patients entered the study (29 men, eight women), aged from 41 to 70 years (mean (SD) $57(7)$ years). All the patients were selected on the basis of having chronic left ventricular failure (duration $>3$ months) secondary to ischaemic heart disease and exercise tolerance limited by dyspnoea (New York Heart Association functional class III) despite treatment with digoxin and diuretics. Patients were excluded from the study if they had sustained a myocardial infarction within the previous three months, had valvar heart disease, or obstructive airways disease.

Table 1 summarises the patient characteristics. The presence of coronary artery disease was confirmed in all patients: in 23 by coronary angiography ( 18 of whom had a previous myocardial infarction) and in the remaining 14 by documented transmural myocardial infarction. Seven patients in each group were receiving antianginal treatment in the form of isosorbide dinitrate $(20-90 \mathrm{mg} /$ day $)$ or nifedipine (30-

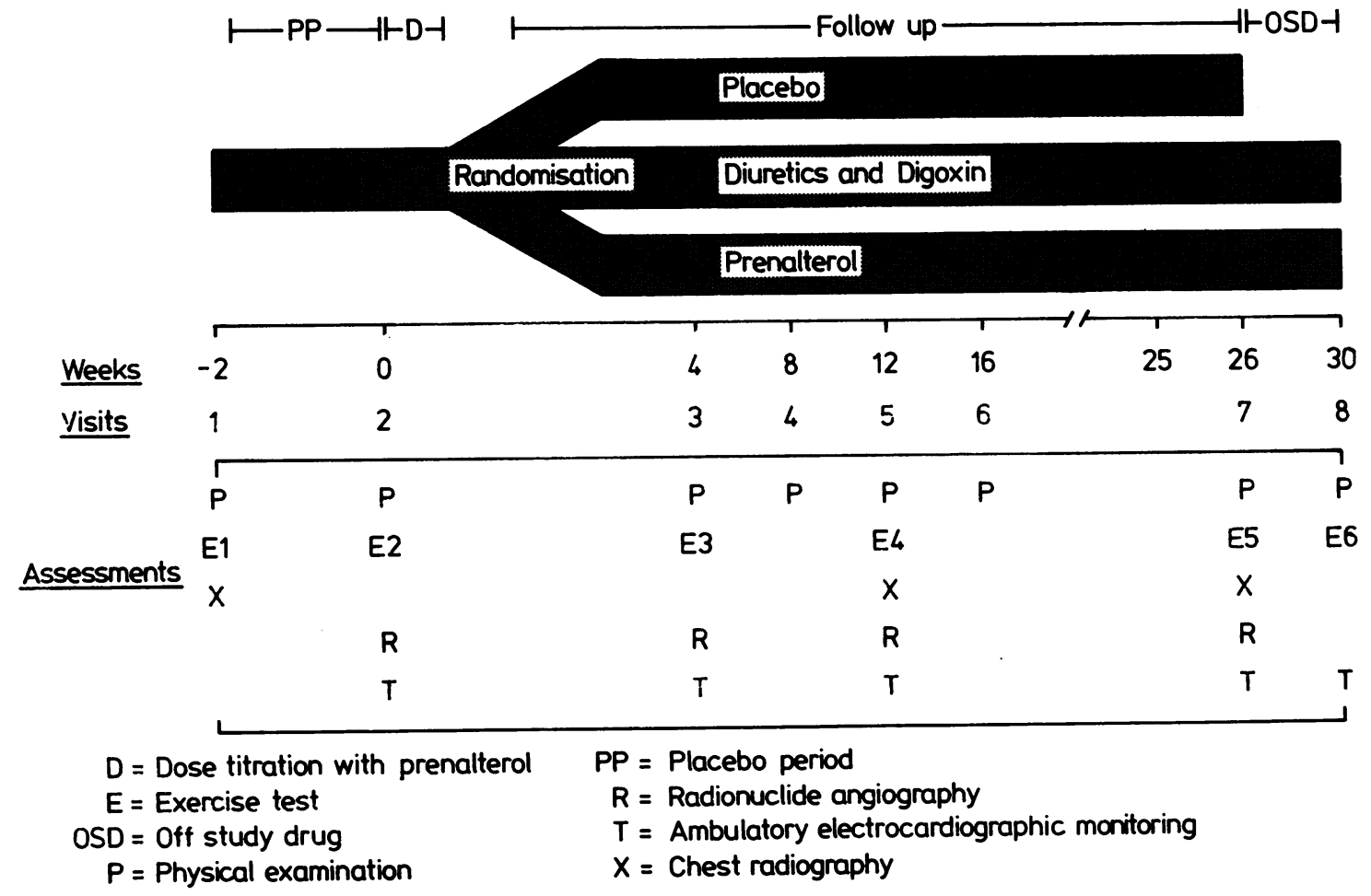

Fig. 1 Study protocol. 
$60 \mathrm{mg} /$ day) or both, which was maintained throughout the study.

\section{STUDY DESIGN}

Figure 1 shows the study design. It consisted of a two week single blind placebo period followed by a single blind dose titration period. Oral prenalterol (prenalterol hydrocholoride controlled release tablets: $\mathrm{AB}$ Hassle) was given in incremental doses of $20 \mathrm{mg}$, $30 \mathrm{mg}$, and $50 \mathrm{mg}$ at two-hourly intervals. The optimal dose was judged to be that which resulted in a moderate increase in resting heart rate of not more than 10 beats/min, with or without a rise in systolic blood pressure of not more than $20 \mathrm{~mm} \mathrm{Hg}$, and which could be tolerated without unwanted effects. Patients were then randomised to receive the optimal dose of prenalterol or matching placebo for six months. At the end of this period the treatment was withdrawn in a double blind fashion and a final assessment made one month later. The assessments were performed at the same time of day and at the same time after tablet administration in each patient. The doses of digoxin, diuretics, and other medication were kept constant throughout the study except where clinical deterioration necessitated alteration.

The protocol for this study was accepted by the United Kingdom Committee on Safety of Medicines under the Clinical Trial Certificate (CTC) scheme. The local ethical committees approved the study, which was performed according to the principles of the World Health Association's Declaration of Helsinki. Written consent was obtained from each patient.

\section{Methods}

\section{TRIAL PROCEDURE}

Clinical assessments-At each visit the patient and examining physician independently were asked to assess progress from the previous visit on a scale 1 to 7: 1, markedly worse; 2, moderately worse; 3 , slightly worse; 4, about the same; 5 , slightly improved; 6, moderately improved; 7, markedly improved. The patient's subjective score (based on symptoms) and the physician's objective score (based on physical signs) were then combined to give an overall clinical score. The baseline clinical score was taken to be $8(4+4)$ in every case and at each visit the score increased or decreased in a cumulative fashion depending on the degree of changes from the previous visit. The patient's NYHA functional classification was also estimated by the physician.

Exercise tests-Maximal symptom limited exercise tests were performed on an electrically braked upright bicycle ergometer using a protocol which commenced at $20 \mathrm{~W}$ for two minutes and subsequently increased by $10 \mathrm{~W}$ per minute. The patient's heart rate and rhythm were continuously monitored and the heart rate and systolic blood pressure recorded at the end of each workload. Blood pressure was measured using a standard mercury sphygmomanometer.

Radionuclide angiography-Radionuclide angiography was performed following in vivo red cell labelling with $740 \mathrm{MBq}$ technetium $99 \mathrm{~m}$. Image data were aquired using a mobile gammacamera in the anterior and left anterior oblique projections at rest and the left anterior oblique projection during supine dynamic exercise. Count dependent global left ventricular ejection fraction was calculated from the background corrected time-activity curves from resting and exercise left anterior oblique images. Exercise was performed supine using an electrically braked bicycle ergometer. A single step protocol was used with a work level approximately $50 \%$ of the erect maximal level previously determined. A total of four minutes supine exercise was performed with image data acquisition during the last three minutes.

Chest radiography-A standard posteroanterior chest $x$ ray film was taken at six feet for determination of the cardiothoracic ratio.

Ambulatory electrocardiographic monitoringStandard 24 hour single channel recordings were made using an Oxford Medical Series 4.24 portable cassette recorder (Oxford Electronic Instruments, Oxford). Analysis of the recordings was carried out using a Pathfinder Mark II (Reynolds Medical Instruments) by a single operator. The results were reported using the Lown grading system. ${ }^{20}$

Haematological and biochemical analyses-Blood samples for routine haematological and biochemical tests and samples for subsequent plasma prenalterol ${ }^{21}$ and digoxin assay were taken at the time of each clinical assessment.

Unwanted effects-Any unwanted effects were recorded at the time of each clinical assessment.

\section{STATISTICAL ANALYSIS}

All results are expressed as mean (standard deviation). Baseline values for resting and exercise heart rate and blood pressure were calculated as the mean of the two pretreatment measurements, whereas for radionuclide angiography and chest radiography the single pretreatment value was used. Student's $t$ test for unpaired data was used to compare the differences in the baseline values and changes from baseline between the two groups, while a Student's paired $t$ test was used to test the significance of the change from baseline within each treatment group. A Wilcoxon sum of ranks test was used to compare the cumulative clinical score between the two treatment groups. 


\section{Results}

Nineteen patients were randomised to receive prenalterol and 18 to receive placebo. The patients were well

Table 2 Number of deaths and withdrawals

\begin{tabular}{lll}
\hline & $\begin{array}{l}\text { Prenalterol } \\
(n=19)\end{array}$ & $\begin{array}{l}\text { Placebo } \\
(n=18)\end{array}$ \\
\hline Reason for death: & 1 & 2 \\
$\quad$ Sudden cardiac death & 1 & 0 \\
Progressive severe cardiac failure & 1 & 2 \\
$\quad$ with Mobitz type II heart block & 1 & 0 \\
$\quad$ Total & 2 & 0 \\
Events leading to withdrawal: & 1 & 2 \\
Progressive cardiac failure & 1 & 1 \\
Acute myocardial infarction & 0 & 3 \\
Increased angina pectoris & 0 & \\
Acute onset diabetes mellitus & 2 & \\
Total & &
\end{tabular}

No statistically significant differences prenalterol $v$ s placebo. matched at entry with no significant differences between the treatment groups (Table 1).

The optimal doses of prenalterol determined by dose titration were as follows: $100 \mathrm{mg}$ twice daily, 17 patients (16 male, one female); $50 \mathrm{mg}$ twice daily, 15 patients (nine male, six female); and $20 \mathrm{mg}$ twice daily, 5 patients (four male, one female).

\section{DEATHS, WITHDRAWALS, AND PROTOCOL} VIOLATIONS

Two patients in each group died during the study, and two patients taking prenalterol and three placebo were withdrawn from the study (Table 2). During the study period the dose of diuretic (frusemide) had to be increased in two patients, from $80 \mathrm{mg}$ to $160 \mathrm{mg} /$ day in one case and from $80 \mathrm{mg}$ to $240 \mathrm{mg} /$ day in the other, because of deteriorating heart failure. Both patients were in the placebo group.

Table 3 Results of assessments made throughout the trial. Values are mean (SD) (figures in square parentheses are numbers of patients)

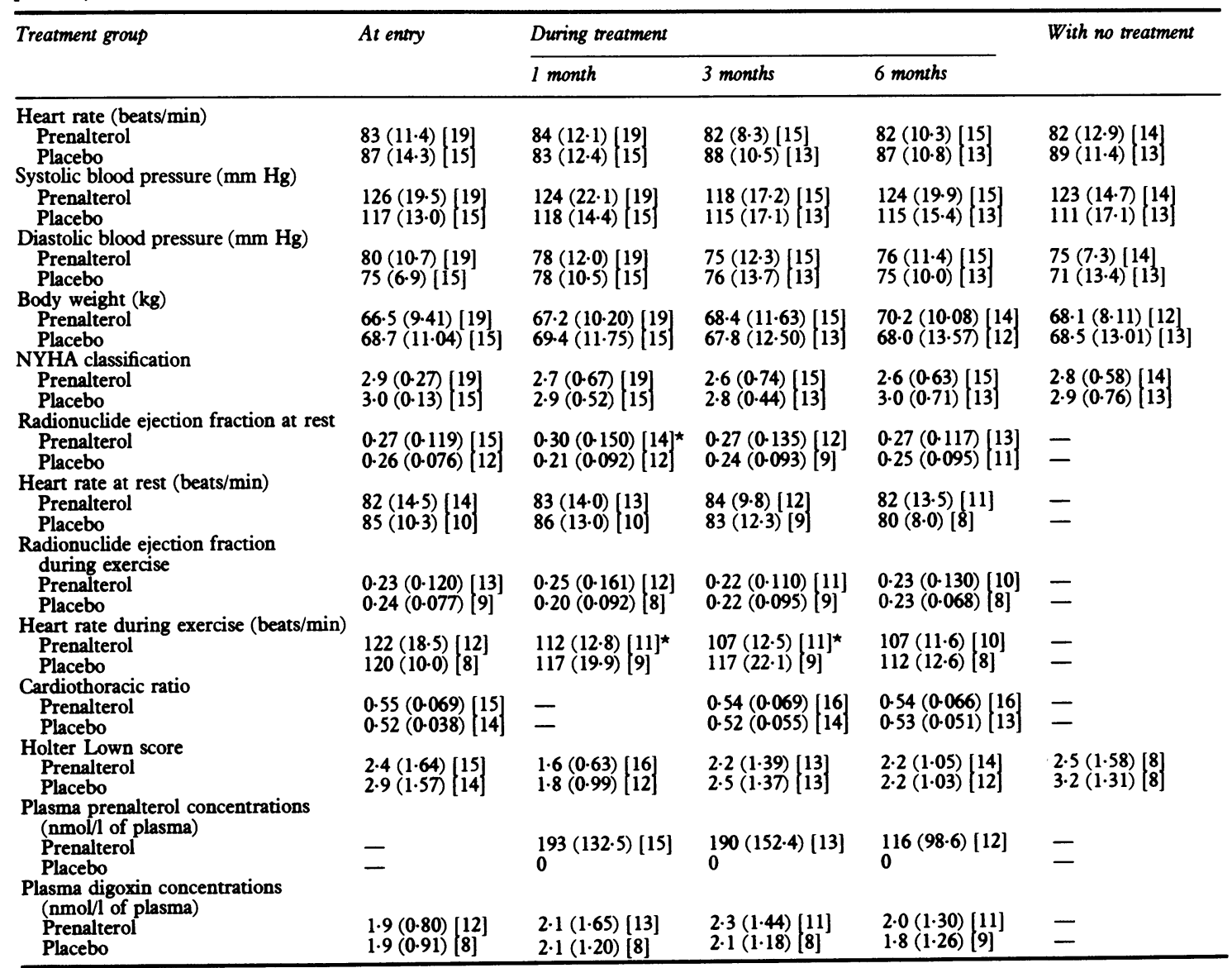

${ }^{\star} \mathrm{p}<0.05$ between the treatment groups. 


\section{RESTING OBSERVATIONS}

Table 3 shows resting heart rate and blood pressures. There were no significant differences between the groups before or during the study.

\section{CLINICAL SCORES AND NYHA CLASSIFICATION}

Figure 2 summarises the clinical scores. In the prenalterol group the increase in clinical scores corresponds to moderate improvement at three and six months. Fourteen of the 19 patients showed a positive clinical response with an increased score. In the placebo group the increase in clinical score corresponds to slight improvement, with 10 of the 18 patients having a small increase in score. The standard deviations (SD) for this group were large in contrast to the prenalterol group, which is a reflection of the variability in clinical response in the placebo group. Statistical significance (Wilcoxon test) was not reached for the differences in cumulative clinical score between the prenalterol and placebo groups.

The NYHA classification (Table 3 ) showed a trend in favour of the prenalterol group which was not statistically significant.

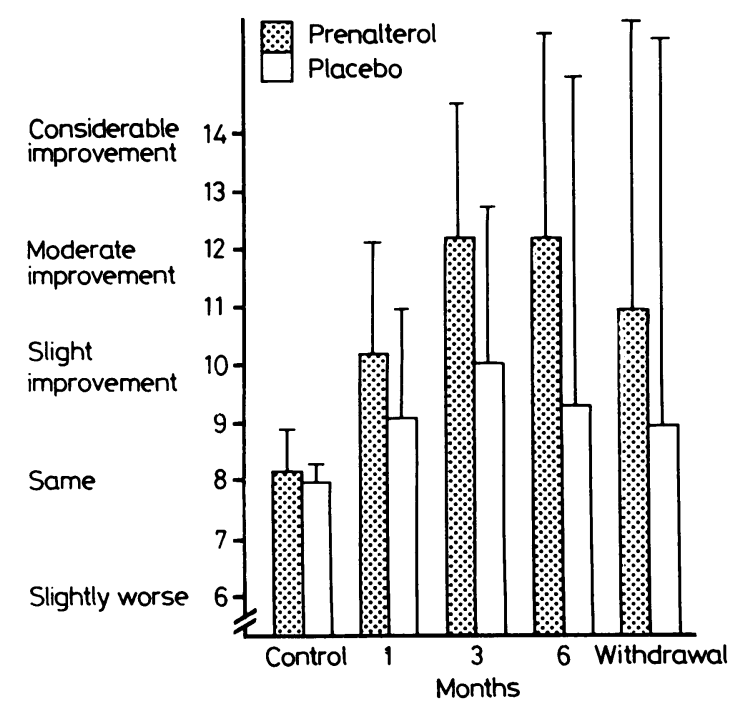

Fig. 2 Mean clinical scores for patients treated with prenalterol or placebo. Bars denote $S D$.
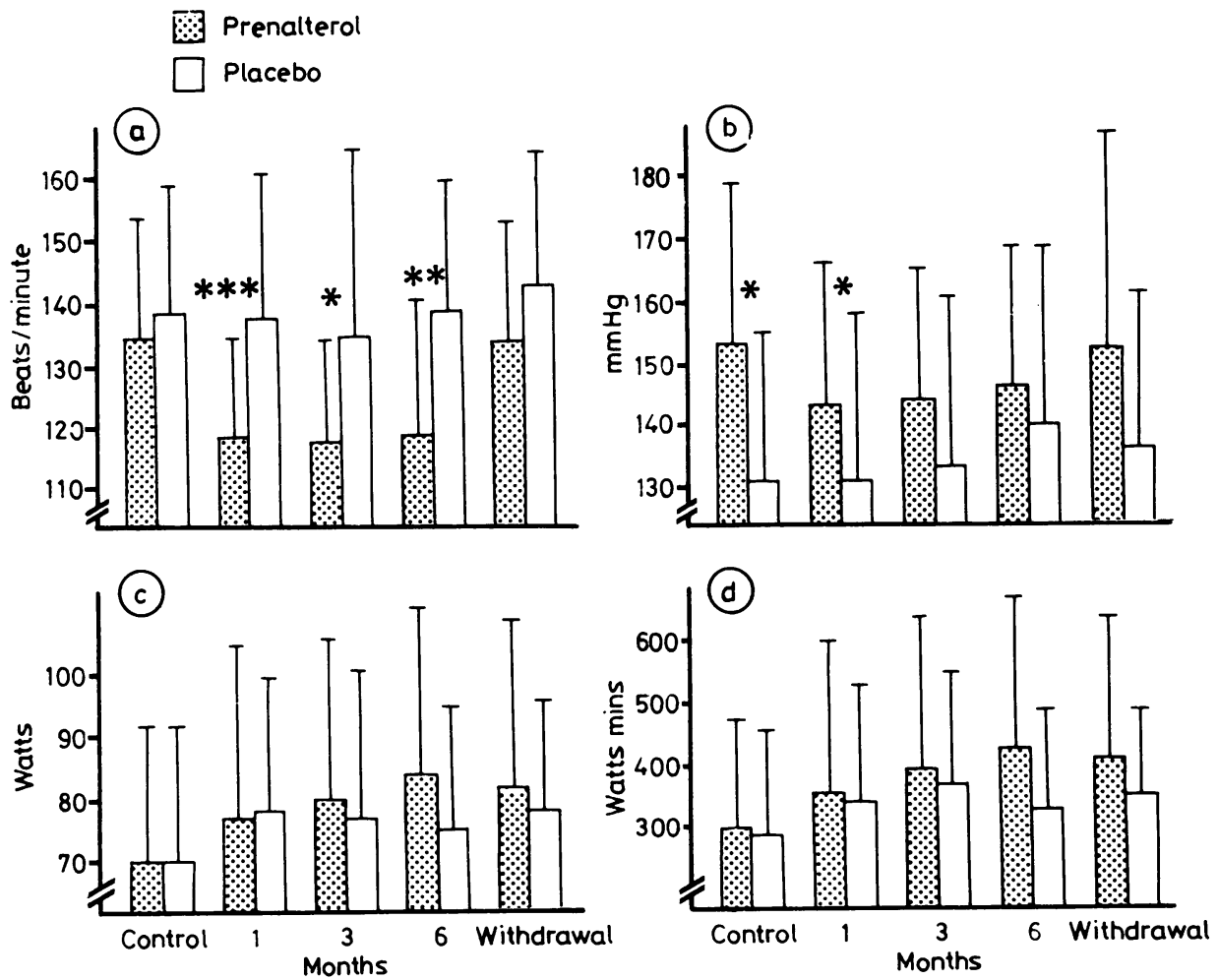

Fig. 3 Maximal exercise test results for patients treated with prenalterol or placebo: (a) maximum heart rate; (b) systolic blood pressure at end of exercise; (c) maximum workload; and (d) total work. Values are mean (SD). $\star_{p}<0.05 ;{ }^{\star} \star_{p}<0.01 ;{ }^{\star \star \star} p<0.001$ (between groups). 
EXERCISE TESTS

The exercise tests were performed without incident. The limiting symptom was breathlessness or fatigue or both in all cases throughout the study. Figure 3 shows the results.

Maximum heart rate was significantly reduced in the prenalterol group at one month $(p<0.001)$, three months $(p<0.05)$, and six months $(p<0.01)$ compared with placebo. On drug withdrawal there was a return to control values.

During the control period systolic blood pressure at the end of exercise was significantly higher in the prenalterol group than in the placebo group $(p<0.05)$. There was a tendency for the systolic blood pressure to be reduced in the prenalterol group during the treatment period, and this change reached statistical significance compared with placebo after one month $(\mathrm{p}<0.05)$. There was little change in the placebo values.

Rate pressure products were calculated from the above data and were found to be significantly reduced in the prenalterol group at one month $(p<0.001)$, three months $(p<0.05)$, and six months $(p<0.01)$ compared with placebo.

The maximum workload (watts) achieved by the prenalterol group was significantly increased at one month $(p<0.05)$ and six months $(p<0.01)$ compared with control values. There was a significant increase in the placebo group at one month $(p<0.05)$, but there were no significant differences between the treatment groups. On drug withdrawal there was no significant change in maximum workload achieved in either group.

The total work performed (watts mins) by the prenalterol group was significantly increased at one month $(p<0.05)$ and at six months $(p<0.01)$ compared with control values. In the placebo group there was a significant improvement at one month $(p<0.05)$ compared with control values, but this was not maintained. There were, however, no significant differences between the groups.

\section{RADIONUCLIDE ANGIOGRAPHY AND CHEST RADIOGRAPHY}

Seven of the patients were in atrial fibrillation and were not studied. Table 3 shows the radionuclide left ventricular ejection fractions at rest and during exercise. There were no significant changes in the resting or exercise ejection fractions within the treatment groups during the study. Nevertheless, the differences between the groups for resting values alone at one month achieved statistical significance $(p<0.05)$. The heart rate during supine exercise was significantly reduced in the prenalterol group compared with placebo at one and three months $(\mathrm{p}<0.05)$ (Table 3$)$.

There was little change (NS) in the cardiothoracic ratio in both groups during the study (Table 3).

\section{AMBULATORY ELECTROCARDIOGRAPHIC MONITORING}

Cardiac arrhythmias were often recorded in the absence of symptoms in both groups at entry and during the trial period. Nevertheless, there was no significant difference in the occurrence of ventricular arrhythmias (Lown score) during the trial between the treatment groups (Table 3).

HAEMATOLOGICAL AND BIOCHEMICAL ANALYSES No significant changes were observed in any of the standard haematological or biochemical analyses during the study period. In particular, there were no changes in serum glucose, potassium, or creatinine concentrations. Plasma digoxin and prenalterol concentrations confirmed drug compliance in all patients (Table 3).

\section{UNWANTED EFFECTS}

Table 4 shows the unwanted effects reported by patients. There was little difference in the incidence of unwanted effects between the groups. Four patients in each treatment group had the dose of study drug reduced because of unwanted effects. Digoxin was reduced in one patient in the placebo group and isosorbide dinitrate in one patient on prenalterol with good effect.

Table 4 Unwanted effects

\begin{tabular}{|c|c|c|}
\hline Effects & Prenalterol & Placebo \\
\hline \multicolumn{3}{|l|}{ Cardiac: } \\
\hline Increased angina pectoris & 3 & 5 \\
\hline \multicolumn{3}{|l|}{ Gastrointestinal: } \\
\hline Heartburn & 2 & 0 \\
\hline Nausea & 1 & 3 \\
\hline Epigastric pain & 1 & 1 \\
\hline Flatulence & 1 & 1 \\
\hline \multicolumn{3}{|l|}{ Central nervous system: } \\
\hline Headache & 2 & 1 \\
\hline Insomnia & 1 & 0 \\
\hline Tiredness & 1 & 1 \\
\hline \multirow{2}{*}{\multicolumn{3}{|c|}{ Allergic reactions: }} \\
\hline & & \\
\hline Itchy eyes & 1 & 0 \\
\hline \multicolumn{3}{|l|}{ Other: } \\
\hline Flushing & 1 & 0 \\
\hline Tinnitus & 1 & $\mathbf{0}$ \\
\hline Bizarre dreams & 1 & 0 \\
\hline
\end{tabular}

No statistically significant differences prenalterol $v$ s placebo.

\section{Discussion}

In this study long term oral prenalterol treatment has been shown to be clinically beneficial, tending to improve symptoms and exercise tolerance in patients with chronic ischaemic left ventricular failure. These 
benefits appear to have occurred in the absence of any detectable improvement in left ventricular performance and were associated with a heart rate sparing effect during exercise. We also noted pronounced placebo response.

The selective beta ${ }_{1}$ agonist, prenalterol, has been shown to have a significant positive inotropic effect when given intravenously, $22-25$ and recently the inotropic effect has been confirmed during an acute oral dose-response study, ${ }^{17}$ and during a short term oral double blind crossover study against placebo. ${ }^{18}$ These changes have occurred in the absence of alterations in left ventricular preload and afterload. The improvement in exercise capacity which we found provides some indirect evidence of a positive inotropic effect, which was not detected by radionuclide angiography. Small changes in left ventricular ejection fraction are difficult to detect in patients with dilated poorly contracting hearts but could be of clinical importance. The lack of correlation between exercise capacity and left ventricular ejection fraction has been well documented in patients with left ventricular failure, ${ }^{2627}$ and compensatory mechanisms have been suggested to explain this. ${ }^{28}$

Chronic treatment with beta agonists could possibly produce tachyphylaxis owing to activation of the renin-angiotensin system ${ }^{29}$ and "down regulation" of beta receptors. ${ }^{30}$ It is interesting that we did not observe such tachyphylaxis. There was a small but insignificant weight gain in the prenalterol group. Nevertheless, none of these patients developed oedema or other symptoms of fluid retention, and we have attributed this increase in weight gain to the improved appetite and general well being observed during prenalterol treatment. Another possible disadvantage of beta stimulation is induction of cardiac arrhythmias and angina. We found no evidence that ventricular arrhythmias increased in the prenalterol group, and only two patients were withdrawn from the study because of increasing angina; both were taking placebo.

The attenuation in heart rate on maximal and submaximal exercise could have been the main way in which benefit was produced. ${ }^{31}$ This attenuation was similar to that observed with conventional beta blocker treatment, even in patients with cardiac failure. ${ }^{32}$ This leads us to propose that prenalterol reduces exercise heart rate by partial beta blockade. Consequently, the theoretical disadvantage of a full beta agonist-namely, increased myocardial oxygen demand-would be prevented. Indeed analysis of the rate-pressure product which approximates to myocardial oxygen consumption ${ }^{33}$ is in keeping with this view. It may also explain our observation that the incidence of angina was not increased and that few arrhythmias were encountered. The finding that pre- nalterol did not depress left ventricular performance supports the fact that it is not a full beta blocker. ${ }^{32}$

The observed clinical improvement in 10 patients in the placebo group warrants further comment. This was perhaps due to the extra interest shown in the patients. They were severely limited by symptoms despite maximal conventional treatment and consequently were grateful for any hope offered by trial treatment. Compliance in such patients is usually excellent and was confirmed in this study.

Our study was designed to determine whether prenalterol produced improvement in exercise tolerance in patients with severe resistant heart failure. This assessment was used as an objective way of determining quality of life. The results show a definite trend towards improvement. The fact that evidence of improvement in left ventricular performance was lacking does not detract from the results.

Two placebo controlled studies have recently reported that prenalterol was of little benefit. ${ }^{34} 35$ Why are our findings different? In both of these studies several of the patients had cardiomyopathy with normal coronary arteries or left ventricular failure of unknown origin, and some of the patients were in NYHA class IV. In contrast, all our patients had left ventricular failure of ischaemic origin and class IV patients were specifically excluded so that we studied a more homogenous group of patients. Additionally, the greater number of patients in our study may have enabled us to observe changes not apparent in the small groups of Lambertz $(n=16)^{34}$ and Currie $(n=6) .{ }^{35}$ The dose of prenalterol used in the Lambertz study ${ }^{34}$ was lower than that which we used with resulting serum concentrations approximately half of those we obtained. In Currie's study ${ }^{35}$ the treatment period was short so that it would have missed the clinical benefits which became apparent in our study after three months' treatment.

In conclusion, we found that prenalterol was well tolerated and no serious unwanted effects were observed. It appeared to be tolerated well in patients with angina as well as dyspnoea. The chronic effect of this partial beta ${ }_{1}$ agonist on the myocardial beta receptors and on the circulating endogenous catecholamines should be investigated to further elucidate its mode of action. Partial beta ${ }_{1}$ agonist treatment appears to be of benefit in patients with ischaemic failure who are symptomatic despite maximal conventional treatment.

We thank Dr R A Elton, Edinburgh University, for kindly providing the statistical advice, and Dr B Tiplady, Astra Clinical Research Unit, for performing the data analysis, Astra Clinical Research Unit, Edinburgh, for generous financial support, and AB Hassle, Molndal, Sweden, for providing the prenalterol tab- 
lets and for performing plasma analysis for prenalterol and digoxin.

\section{References}

1 Braunwald E. Heart failure: pathophysiology and treatment. Am Heart f 1980; 102: 486-90.

2 Bruschke AVG, Proudfit WL, Sones FM Jr. Progress study of 590 consecutive nonsurgical cases of coronary disease followed 5-9 years. II Ventriculographic and other correlations. Circulation 1973; 47: 1154-63.

3 Selzer A. Digitalis in cardiac failure. Do benefits justify risks? Arch Intern Med 1981; 141: 18-9.

4 Johnston GD, McDevitt DG. Is maintenance digoxin necessary in patients with sinus rhythm? Lancet 1979; i: 567-70.

5 Petch MC. Digoxin for heart failure in sinus rhythm. Thorax 1979; 34: 147-9.

6 Murray RG, Tweddel AC, Martin W, Pearson D, Hutton I, Lawrie TDV. Evaluation of digitalis in cardiac failure. $\mathrm{Br} \mathrm{Med}$ F 1982; 284: 1526-8.

7 Arnold SB, Byrd RC, Meister W, et al. Long term digitalis therapy improves left ventricular function in heart failure. $N$ Engl f Med 1980; 303: 1443-8.

8 Lee DC, Johnson RA, Bingham JB, et al. Heart failure in outpatients: a randomized trial of digoxin versus placebo. $N$ Engl f Med 1982; 306: 699-705.

9 Chatterjee K, Parmley WW. Vasodilator therapy for chronic heart failure. Ann Rev Pharmacol Toxicol 1980; 20: 475-512.

10 Breckenridge A. Vasodilators in heart failure. $\mathrm{Br} \mathrm{Med} \mathrm{J}$ 1982; 284: 756-6.

11 LeJemtel TH, Keung E, Sonnenblick EH, et al. Amrinone: a new non-glycosidic non-adrenergic cardiotonic agent effective in the treatment of intractable myocardial failure in man. Circulation 1979; 59: 1098104.

12 Anonymous. Sympathomimetics in heart failure. Drug Ther Bull 1982; 20: 77-9.

13 Anonymous. Beta agonists and heart failure. Lancet 1983; ii: $1063-4$.

14 Dawson JR, Bayliss J, Norrell MS, et al. Clinical studies

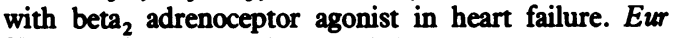
Heart f 1982; 3 (suppl D): 135-41.

15 Mattsson H, Hedberg A, Carlsson E. Basic pharmacological properties of prenalterol. Acta Med Scand 1982; 659 (suppl): 9-37.

16 Detry J-MR, Decoster PM, Brasseur LA. Hemodynamic effects of Corwin (ICI 118, 587), a new cardioselective beta-adrenoceptor partial agonist. Eur Heart $\mathcal{F}$ 1983; 4: 584-91.

17 Petch MC, Wisbey C, Ormerod O, Scott C, Goodfellow RM. The acute haemodynamic effects of oral prenalterol in severe heart failure. Br Heart f 1984; 52: 49-52.

18 Hutton I, Clark RS, McKillop JH, Martin W, Tweddel AC. A controlled trial of oral prenalterol in patients with chronic cardiac failure. Eur Heart $\mathcal{f}$ 1983; 4 (suppl E): 27.

19 Hendry WG, Comerford MB, Besterman EMM. A dose response study with oral prenalterol in patients with chronic congestive cardiac failure. Clin Cardiol 1984; 7:
23-8.

20 Lown B, Wolf $M$. Approaches to sudden death from coronary heart disease. Circulation 1971; 44: 130-42.

21 Degen PH, Ervik M. Determination of prenalterol in plasma and in urine by gas-liquid chromatography. $\mathcal{F}$ Chromatogr 1981; 222: 437-44.

22 Hutton I, Murray RG, Boyes RN, Rae AP, Hillis WS. Haemodynamic effects of prenalterol in patients with coronary heart disease. Br Heart $\mathcal{F}$ 1980; 43: 134-7.

23 Kendall MJ, Goodfellow RM, Westerling S. Prenaltero-a new cardioselective inotropic agent. $\mathcal{F}$ Clin Hosp Pharm 1982; 7: 107-18.

24 Kupper W, Schutt M, Hamm CW, Kuck KH, Hanrath $P$, Bleifeld $W$. Haemodynamic and cardiac metabolic effects of the new $\beta_{1}$ agonist prenalterol in patients with cardiac failure. Eur Heart $\mathcal{F}$ 1983; 4: 573-83.

25 Erbel R, Meyer J, Lambertz H, et al. Hemodynamic effects of prenalterol in patients with ischemic heart disease and congestive cardiomyopathy. Circulation 1982; 66: 361-9.

26 Franciosa JA, Park M, Levine TB. Lack of correlation between exercise capacity and indexes of resting left ventricular performance in heart failure. Am $\mathcal{F}$ Cardiol 1981; 47: 33-9.

27 Benge W, Litchfield RL, Marcus ML. Exercise capacity in patients with severe left ventricular dysfunction. Circulation 1980; 61: 955-9.

28 Litchfield RL, Kerber RE, Benge JW, et al. Normal exercise capacity in patients with severe left ventricular dysfunction: compensatory mechanisms. Circulation 1982; 66: 129-34.

29 Fitzpatrick D, Ikram H, Nicholls MG, Espiner EA. Hemodynamic, hormonal and electrolyte responses to prenalterol infusion in heart failure. Circulation 1983; 67: 613-9.

30 Colucci WS, Alexander RW, Williams GH, et al. Decreased lymphocyte beta-adrenergic receptor density in patients with heart failure and tolerance to the beta adrenergic agonist pirbuterol. $N$ Engl f Med 1981; 305: 185-90.

31 Swedberg K, Hjalmarson A, Waagstein F, Wallentin I. Beneficial effects of long-term beta-blockade in congestive cardiomyopathy. Br Heart $f$ 1980; 44: 117-33.

32 Ikram H, Fitzpatrick D. Double-blind trial of chronic oral beta blockade in congestive cardiomyopathy. Lancet 1981; ii: 490-3.

33 Blackburn H, Winkler G, Vilandre J, Hodgson J, Taylor HL. Exercise tests. Comparison of the energy cost and heart rate response to five commonly-used single-stage, non-steady-state, submaximal work procedures. In: Brunner D, Jokl E, eds. Physical activity and aging: with special reference to the effect of exercise and training on the natural history of arteriosclerotic heart disease. Basel: Karser, 1970: 28-36. (Medicine and Sport, Vol 4.)

34 Lambertz H, Meyer J, Erbel R. Long-term hemodynamic effects of prenalterol in patients with severe congestive heart failure. Circulation 1984; 69: 298-305.

35 Currie PJ, Kelly MJ, Middlebrook K, et al. Acute intravenous and sustained oral treatment with the beta agonist prenalterol in patients with chronic severe cardiac failure. Br Heart $\mathcal{F}$ 1984; 51: 530-8. 